\title{
ASPEK SUPRAGSEMENTAL SEBAGAI PENDUKUNG KONSTRUKSI TEMA-REMA DALAM BAHASA JAWA BANYUMAS
}

\section{SU PRAG SEMENTAL ASPECT AS SUPPORTING THE THEME-RHEME CONSTRUCTION IN JAVA BANYUMAS LANGUAGES}

\author{
Restu Sukesti \\ Balai Bahasa Provinsi D aerah Istimewa Yogyakarta \\ Pos-el: restu_sukesti@yahoo.co.id, Telepon: 08121557130
}

\begin{abstract}
A bstract
Themerheme construction is a part of the univesality langrage in the world. The most impatant aspet as the suppoter of themerhemeconstrution is suprasegmental aspet, which is intanation rde With that intonation rde, themerheme unsureand variation can bedktemined In a themerheme construction rearh in JavaneseBanyumas based onintonationrdererch, found that theeisuniquecharaderisticof theme, rheme, and supplement unsure It is found that therearesix themerheme construction rdes in JavaneseBanyumas based on theintonation rdeas well. Marever, fiveof thosesix rdes can dhangeintoandher rdebecause of intonation rdedanging Thus suprasegental aspet has hugeinfluencetothethemerhemeconstruction.
\end{abstract}

Keyw ords: suprasegmental, intanation, theme, heme, suplemen

\begin{abstract}
Abstrak
Konstruksi tema-rema merupakan salah satu ciri keuniversalan bahasa-bahasa di dunia. Aspek yang terpenting sebagai pendukung konstruksi tema-rema ialah aspek suprasegmental, yaitu pola intonasi. D engan pola intonasi tersebut, unsur-unsur dan variasi konstruksi tema-rema dapat ditentukan. D alam kajian konstruksi tema-rema dalam bahasa Jawa Banyumas, berdasarkan kajian pola intonasinya, ditemukan kekhasan unsur tema, rema, dan suplemen. Berdasarkan pola intonasi itu pula, dalam bahasa Jawa Banyumas ditemukan enam pola konstruksi tema-rema. Lima di antara enam pola tersebut dapat berubah menjadi pola lain karena perubahan pola intonasinya. Dengan demikian, aspek suprasegmental sangat berpengaruh terhadap konstruksi tema-rema.
\end{abstract}

Kata kunci: suprasegmental, intonasi, tema, rema, suplemen

\section{PENDAHULUAN}

Konstruksi tema-rema ialah bentuk sintaktik yang dibangun atas pementingan dan kebaruan informasi. Unsur tema dianggap sebagai informasi lama dan kurang penting; unsur rema diangap informasi baru dan paling penting. Konstruksi tema rema ditandai dengan intonasi (Halliday 2004: 37). Oleh karena itu, Halim (1984: 121) menyebutkan bahwa fenomena topik (dianalogikan sebagai tema) dan sebutan (dianalogikan sebagai rema) dalam bahasa Indonesia dapat dijelaskan hanya dalam hal intonasi (prosodi). Ciri intonasi itu pada pola topik-sebutan (tema-rema) bersifat stabil. Oleh karena itu, Suparno (1993) telah melakukan penelitian tema-rema dalam bahasa Indonesia lisan di Kotamadya Malang dengan berpijak pada ciri intonasi.

Konstruksi tema-rema dalam suatu bahasa berhubungan dengan ciri intonasi (Halim 1984: 115121; Suparno 1993: 28). Sementara itu, telah diketahui bahwa bahasa, pada umumnya memiliki dua aspek, yaitu suprasegmental dan segmental 
merupakan ciri universal pada sebagian besar bahasa-bahasa manusia di dunia. Oleh karena itu, konstruksi tema-rema juga merupakan ciri universal pada bahasa-bahasa yang ada, termasuk dalam bahasa Jawa Banyumas.

\section{LANDASAN TEORI}

Kalimat berkonstruksi tema-rema sangat umum terdapat dalam bahasa Jawa (sesuai dengan hasil kajian G loria-Poedjosoedarmo (1974); A rifin (1985); dan Poedjosoedarmo (1998)). Hal itu terjadi karena bahasa Jawa lebih mengutamakan penopikan kalimat dan urgensi informasi. Pernyataan itu bersesuaian dengan pendapat Poedjosoedarmo (1974, Verhaar (1970), dan Subroto (1991). Bahkan, Baryadi (2002:88- 98) telah memaparkannya secara teoretis tentang urgensi informasi dan status informasi dalam wacana dan dalam kalimat (juga kalimat yang berkonstruksi tema-rema). D alam masalah urgensi informasi, unsur yang terpenting di dalam konstruksi tema-rema ialah remanya. Hal itu disebabkan bahwa pola intonasi pada rema tersebut hanya ada satu, yaitu / 231t/ dan merupakan unsur yang terpenting karena sebagai informasi terbaru. Pandangan tersebut sesuai dengan Poedjosoedarmo (1998:13), seperti berikut.

"Karena bahasa Jawa memiliki sistem intonasi kalimat yang berpola secara 'ajek' maka pola-pola intonasi itu pun dapat membawakan makna. Yang perpola 231 tentu mengandung informasi baru dan yang ada di depannya (maksudnya ialah tema) tentu merupakan informasi pendahulu yang menghubungkan informasi terbaru itu dengan sesuatu yang ada dalam wacana."

Dengan itu, di mana pun posisi rema, pola intonasinya tidak berubah, lain halnya dengan pola intonasi tema dan pola intonasi suplemen (ekor) dapat berubah karena posisi, pernyataan itu sesuai dengan Halim (1984) dan Suparno (1993). D engan itu, dalam penelitian ini akan dilihat apakah konstruksi tema-rema dalam bahasa Jawa Banyumas lisan sama dengan konstruksi tema-rema dalam bahasa Jawa secara umum (standar), yaitu mengutamakan penopikan kalimat dan urgensi informasi.

Dalam konstruksi tema-rema, intonasi tampaknya menjadi aspek yang sangat penting dalam penentuan konstruksi tema-rema, seperti apayang diungkapkan oleh Halim (1984) dan Suparno (1993) dan seperti yang telah dilakukan dalam penelitian G loria-Poedjosoedarmo (1974), Wedhawati, dkk. (1979), dan Poedjoesoedarmo (1998), tetapi belum dilakukan pada Soemarno (1971).

\section{PEMBAHASAN}

Berdasarkan data bahasaJawa Banyumas yang diperoleh terdapat enam tipe variasi konstruksi tema-rema. Penipean itu berdasarkan atas jumlah kontur yang masing-masing kontur berisi unsur (konstituen) yang berbeda, yaitu unsur tema, rema, dan suplemen. Penentuan unsur itu berdasarkan pola intonasi, informasi, dan posisi. Dalam penipean tersebut dihasilkan bahwa setiap konstruksi pasti memiliki unsur rema, dan unsur itu hanya satu. Unsur lain, tema dan suplemen dapat hadir atau tidak, dan kehadirannya dapat dalam satu kontur atau lebih. Tema terletak pada awal konstruksi dan suplemen pada akhir konstruksi atau pada tengah konstruksi. Berikut enam tipe konstruksi tema-rema dalam bahasa Jawa Banyumas: (i) $\mathrm{R}$ (tipe 1);(ii) $\mathrm{T} \mathrm{R}$ (tipe 2); (iii) (T) $\mathrm{T} \mathrm{R}$ (tipe 3); (iv) R Sup (tipe 4);(v) R Sup (Sup) (tipe 5); dan (vi) T Sup R (tipe 6).

\subsection{Intonasi pada Tiap-Tiap Unsur}

\subsubsection{Intonasi Tema dan Penentuan Tema}

Tema terletak pada awal kontruksi atau terletak sebelum rema dengan berintonasi 2-23n atau 2-33n. Contohnya dalam bahasa Jawa Banyumas ialah sebagai berikut. 
(1) \# Ag் dhongpatingprengut ya/ enyongbingung// kaya kume\#

/ agi dòoK patiK preKut ya êñoK biKuK kaya kuwé/

$$
\text { \# 2-23n // 231t // 221t \# }
$$$$
\mathrm{T} \quad \mathrm{R} \quad \text { Sup }
$$

Saat sedang semua bermuka masam ya/ / saya bingung/ / seperti itu

'Saat semua sedang bermuka masam ya saya bingung begitu'.

(1a) \# Enyonglingung / agं dhongpatingprengat// kaya kume\#

/ êñoK biKuK agi dòoK patiK prêKut kaya kuwél

$$
\begin{array}{ccl}
\text { \# 231t / } 222 \text { // } & \text { 221t \# } \\
\text { R Sup Sup }
\end{array}
$$

Saya bingung/ / saat sedang semua bermuka masam / / seperti itu

'Saya bingung, saat semua sedang bermuka masam, begitu.'

Berdasarkan data yang diperoleh, konstruksi tema-rema dalam bahasa Jawa Banyumas dapat memiliki unsur satu tema atau lebih, seperti pada contoh berikut.

(2) \#Kali Logana kiyd / milind / maning ngidu\#

/ kali logawa kiyé miliné mariK Kidul/

\section{\# 2- 23n// 2-33n// 231t \#}

$\mathrm{T} \quad \mathrm{T} \quad \mathrm{R}$

Sungai Logawa ini/ / alirannya/ / ke selatan kiye/ miline/ tekan

'Sungai Logawa ini, alirannya ke selatan.' kiye/ miline/ tekan

Konstruksi (3.3) memiliki dua tema, yaitu (1) Kali Logavakiyedan (2) milineyang masing-masing berupa satu kontur dengan dipisahkan oleh jeda pendek. Kedua tema tersebut berintonasi 2-33n atau 2-23n.

\subsubsection{Intonasi Rema dan Penentuan Rema}

D alam konstruksi tema-rema, rema merupakan unsur yang paling utama dan paling stabil. Yang dimaksud dengan rema paling utama ialah unsur itu tidak dapat dilesapkan dan yang dimaksud paling stabil ialah unsur itu di mana pun posisinya tetap berintonasi 231t. Hal itu berbeda dengan unsur yang lain, yaitu unsur tema dan suplemen. Tema terletak pada sebelum rema dan dapat berpindah posisi pada sesudah rema. Perpindahan itu menyebabkan perubahan intonasi 2-33n menjadi 222 atau 221t dan status tema berubah menjadi suplemen. Selain itu, baik tema maupun suplemen dapat dilesapkan sehingga rema dapat berposisi sesudah tema atau awal konstruksi. D engan demikian, pembahasan berikut ialah intonasi rema yang berkaitan dengan posisi rema pada sesudah tema dan pada awal konstruksi.

\subsubsection{Intonasi Suplemen dan Penentuan Suplemen}

Suplemen pada konstruksi tema-rema merupakan konstituen tambahan. Artinya, wajib hadirnya bertingkat rendah, informasinya berstatus sebagai informasi lama, dan pementingan informasinya bertingkat kurang penting atau tidak penting. Oleh karena itu, intonasi pada konstituen suplemen berbentuk 222 atau 221t. Berintonasi 222 jika konstituen itu terletak pada tengah konstruksi dan berintonasi 221t jika konstiten itu terletak pada akhir konstruksi. Hal yang juga penting adalah konstituen suplemen tidak mungkin terletak pada awal konstruksi, yang dengan itu awal konstruksi tema-rema tidak mungkin berintonasi 222 apalagi 221t. Dengan demikian, konstituen suplemen hanya terletak pada tengah atau akhir konstruksi.

\subsection{Pola Intonasi Konstruksi Tema-Rema dalam Bahasa Jawa Banyumas}

Berdasarkan data yang diperoleh, dalam bahasa Jawa Banyumas ngoko di Kabupaten Banyu- 
mas terdapat enam tipe pola dasar intonasi. Penipenan itu berpijak pada bentuk pola intonasi pada keseluruhan konstruksi, yaitu (1) pola dasar dengan hanya satu kontur intonasi 231t; (2) pola dasar dengan dua kontur intonasi 2-23n / 221t; (3) pola dasar dengan tiga kontur intonasi 2-23n/ 2-23n/ 231t, dengan catatan bahwa kontur 2-23n dapat lebih dari dua; (4) pola dasar dengan dua kontur intonasi 231t/ 221t; (5) pola dasar dengan tiga kontur intonasi 231t/ 222/ 221t, dengan catatan bahwa kontur 222 dapat lebih dari satu; dan (6) pola dasar dengan tiga kontur intonasi 223n/ 222/ 231t. Keenam tipe pola intonasi konstruksi tema-rema dalam bahasa Jawa Banyumas ngoko di Kabupaten Banyumas akan dijelaskan pada uraian berikut.

\subsubsection{Pola Intonasi Tipe 1}

Bahasa Jawa Banyumas merupakan bahasa komunikasi lisan yang digunakan oleh masyarakat Banyumas di kabupaten Banyumas, terutama dalam situasi tidak resmi. D alam penggunaan itu muncul pola-pola konstruksi tema-rema, yang masing-masing sekurang-kurangnya terdiri atas satu konstituen rema. Bahkan, dalam komunikasi dua arah (dialog) bermunculan konstruksi dengan pola yang berbentuk rema saja, yaitu dengan pola intonasi 231t. Meskipun demikian, komunikasi informasi sudah terbangun dan sudah terjadi saling kesepahaman antara penutur dan pendengar.

Contoh konstruksi tema-rema yang berisi hanya rema dengan pola intonasi 231t ialah sebagai berikut.

(3) \# Ya iya \#

/ ya iya/

\#231t \#

$\mathrm{R}$

Ya iya

'Ya iya.'
Tampak bahwa konstruksi tema-rema yang hanya memiliki satu kontur intonasi 231t sudah dapat mewakili informasi yang akan disampaikan oleh penutur karena informasi itulah hal yang terpenting dan terbaru dan informasi itu disebut rema. D engan itu, meskipun hanya satu kontur intonasi, komunikasi tetap berjalan dengan lancar, dengan syarat hal itu berlangsung dalam situasi dialog. D engan itu pula, konstruksi tema-rema dalam bahasa Jawa Banyumas banyak yang terdiri atas satu konstituen, yaitu konstituen rema.

\subsubsection{Pola Intonasi Tipe 2}

Pola intonasi tipe 2 termasuk yang banyak ditemukan dalam bahasa Jawa ngoko dialek Banyumas. Hal itu disebabkan oleh pola intonasi 2-23n/ 231t berhubungan secara signifikan dengan pola informasi dan status informasi. Pola itu termasuk pola yang standar dalam bahasa Jawa, yaitu pola tema-rema. Berikut adalah contohnya.

(4) \# Anake enyong/ singmbarep/ / wis metas \#

/ anaké ênoK siK mbarêp wis mêntas/ T1 $\mathrm{T} 2$ $\mathrm{R}$

Anaknya saya/ / yang sulung// sudah mentas 'Anak saya, yang sulung sudah berumah tangga.'

Dari contoh tersebut diperlihatkan bahwa bentuk segmental pengisi kontur intonasi tema tidak harus berbentuk nomina atau frasa nomina (yang secara struktural menduduki fungsi subjek kalimat), tetapi berbentuk apa saja. Yang terpenting ialah pola intonasi pada tema 2-23n.

\subsubsection{Pola Intonasi Tipe 3}

Pola intonasi tipe 3 ialah konstruksi temarema dengan tema lebih dari satu. Artinya, tema dapat terdiri atas dua konstituen, tiga konstituen, atau lebih dari itu. Hal itu sangat mungkin terjadi dalam bahasa Jawa standar maupun dalam bahasa Jawa Banyumas meskipun secara struktural ada perbedaan. Namun, secara suprasegmental me- 
miliki kemiripan pola intonasinya. Berikut adalah contoh pola intonasi konstruksi tema-rema tipe 3.

(5) \# Anakeenyang// singmbarep// wis mentas \# / anaké ênoK siK mbarêp wis mêntas/ T1 $\mathrm{T} 2$ $\mathrm{R}$ Anaknya saya/ / yang sulung/ / sudah mentas 'Anak saya, yang sulung sudah berumah tangga.'

Meskipun konstruksi itu memiliki tema lebih dari satu, konstituen rema tetap satu. Seandainya ada konstituen rema yang lain, berarti rema yang lain itu merupakan konstruksi tema-rema tersendiri.

\subsubsection{Pola Intonasi Tipe 4}

Pola intonasi konstruksi tema-rema Tipe 4 ditandai dengan adanya satu konstituen suplemen yang berintonasi 221t. Konstituen itu terdapat pada sesudah rema dan akhir konstruksi. Berikut adalah contohnya.

(6) \# Ratumwis mead/ jee\#

/ ratum wis mérad jéré/

$$
\mathrm{R} \quad \text { Sup }
$$

Ratum sudah minggat// katanya

'Ratum sudah pergi tanpa pamit katanya.'

\subsubsection{Pola Intonasi Tipe 5}

Pola intonasi Tipe 5 menampilkan adanya dua intonasi pada dua konstituen suplemen di belakang rema, dengan yang satu berada pada tengah konstruksi dan yang satu lainnya berada pada akhir konstruksi. Suplemen yang berada pada tengah konstruksi berintonasi 222 dan yang berada pada akhir konstrukis berintonasi 221t. Berikut adalah conto hnya.

(7) \#Cokan bebdh/ / angger mikir kaya kume / enyong\#

/ cokan bêbêh aK gêr mikir kaya kuwé êñoK /
\# 231t // 222 // 221t \#

$\mathrm{R} \quad$ Sup1 Sup2

Kadang tidak mau// kalau memikirkan seperti itu/ / saya

'Kadang tidak mau kalau memikirkan seperti itu, saya.'

(8) \# Senengbangt// munggh käi maning/ kaya kume\#

/ sênêK baK êt muKgah kaji maniK kaya kuwél \# 231t // 222 // 221t \#

\section{$\mathrm{R} \quad$ Sup1 Sup2}

Senang sekali/ / naik haji lagi/ / seperti itu 'Senang sekali menunaikan ibadah haji lagi begitu.'

\subsubsection{Pola Intonasi Tipe 6}

Pola intonasi konstruksi tema-rema Tipe 6 memperlihatkan adanya suplemen pada tengah konstruksi sebelum rema. Konstituen itu berintonasi 222, sama seperti intonasi suplemen pada tengah kalimat sesudah rema. Contoh konstruksi yang memperlihatkan Tipe 6 dengan intonasi suplemen pada tengah kalimat sebelum rema ialah sebagai berikut.

(9) \# Inyong ngomong basa mepes / maen-maed/ / malah ora ngeti \#

/ iñoK KomoK basa mlêpês maèn maèn malah ora Kêrti/

\# 2- 23 n // 222 // 231t \#

$$
\mathrm{T} \quad \operatorname{Sup} \mathrm{R}
$$

Saya berbicara bahasa halus/ / bagus-bagus/ I malah tidak tahu

'Saya berbicara dengan bahasa halus, bagusbagus, malah tidak dimengerti.' 


\subsection{Perubahan Pola Intonasi Konstruksi Tema- Rema dalam Bahasa Jawa Banyumas}

Pada bagian ini akan dibahas perubahan pola intonasi konstruksi tema-rema dalam bahasa Jawa Banyumas ngoko di Kabupaten Banyumas. Perubahan pola intonasi itu meliputi perubahan dari sudut pandang pada masing-masing unsur dalam sebuah konstruksi tema-rema dan perubahan dari sudut pandang pada keseluruhan pola konstruksi. Artinya, pembahasan pertama meliputi perubahan pola intonasi pada unsur-unsur yang mungkin dapat berubah dan pembahasan kedua meliputi perubahan pola intonasi pada keseluruhan pola konstruksi, yang sebenarnya juga disebabkan oleh perubahan unsur-unsurnya. Urutan kedua perubahan pola intonasi itu dilakukan untuk menjaga kejelasan pembahasan.

\subsubsection{Perubahan Pola Intonasi pada Tiap- Tiap Unsur}

Unsur-unsur yang ada pada konstruksi temarema ialah tema, rema, dan suplemen. Sementara itu, yang dapat berubah posisi dan berubah polaintonasinya ialah unsur tema dan suplemen. D engan demikian, pembahasan berikut ialah perubahan intonasi pada tema dan suplemen.

\subsubsection{Perubahan Pola Intonasi pada Tiap- Tiap Tipe Konstruksi Tema-Rema}

Telah diungkapkan sebelumnya bahwa ada enam tipe konstruksi tema-rema dalam bahasa Jawa Banyumas ngoko di Kabupaten Banyumas. $D$ ari keenam tipe tersebut ada tipe yang berisi hanya satu unsur, yaitu Tipe 1 yang hanya berisi satu unsur rema. Telah diterangkan sebelumnya bahwa unsur rema tidak dapat berubah menjadi unsur lain meskipun posisinya dalam konstruksi berubah. D engan itu, perubahan itu tidak menyebabkan perubahan intonasi. Oleh karenanya, Tipe 1 yang hanya berisi unsur rema tidak masuk dalam pembahasan perubahan pola intonasi konstruksi tema-rema.

\subsubsection{Perubahan Pola Intonasi Tipe 2}

Pola intonasi konstruksi tema-rema dalam bahasa Jawa Banyumas ngoko Tipe 2 ialah yang berbentuk 2-23n/ 231t dengan unsur tema - rema (T R). Pola itu sangat sederhana dan standar sebagai pola konstruksi tema-rema. O leh karena itu, perubahan pola intonasi pada konstruksi itu pun hanya ada satu variasi, yaitu perubahan dari 223n/ 231t menjadi 231t/ 221t dengan konstituen tema-rema (T R) menjadi rema-suplemen ( $R$ Sup), seperti pada contoh berikut.

(10) \# Janed/ / maen bangt \#

/ janèn maèn baKêt/

$$
\text { \# 2- 23n// 231t \# }
$$

$\mathrm{T} \quad \mathrm{R}$

Sebenarnya/ / bagus sekali

'Sebenarnya bagus sekali.'

(10a)\# Maen bangt// janen \#

/ maèn baKêt janèn/

\# 231t / / 221t \#

R Sup

Bagus sekali// sebenarnya

'Bagus sekali sebenarnya.'

Perubahan pola intonasi konstruksi temarema Tipe 2 hanya satu variasi, yaitu menjadi pola intonasi 231t/ 221t dengan isi konstituen remasuplemen (R Sup).

\subsubsection{Perubahan Pola Intonasi Tipe 3}

Pola intoasi konstruksi tema-rema dalam bahasa Jawa Banyumas ngoko Tipe 3 ialah berbentuk 2-23n/ 2-23n/ 231t dengan konstituen tema - tema - rema ((T) T R) (tanda kurung yang mengapit T1 mengartikan bahwa tema itu dapat lebih dari satu konstituen). D engan kata lain, pola konstruksi Tipe 3 memiliki dua tema atau lebih. Karena memiliki dua tema atau lebih, perubahan pola intonasinya pun memiliki dua variasi atau lebih, seperti pada contoh berikut. 
(11) \# Kaejed/ / angger pidhato bef / tetep nganges basa Banyumasan \#

/ kaé jên aKgêr pidòato bé têtêp KaKgo basa bañumasan/

\section{\# 2- 23// 2- 23n // 231t \#}

$\mathrm{T} 1 \mathrm{~T} 2 \mathrm{R}$

Itu kan/ kalau pidato saja/ / tetap menggunakan bahasa Banyumas

'Dia kan kalau berpidato saja tetap menggunakan bahasa Banyumas'

(11a)\# Kaejed/ tetep nganggo basa Baryumasan/ / angger pidhato \#

/ kaéjên têtêp KaKgo basa bañumasan aKgêr pidòato /

\section{\#2- 23n// 231t // 221t \# \\ $\mathrm{T} \quad \mathrm{R} \quad$ Sup}

Itu kan/ / tetap menggunakan bahasa Banyumas// kalau pidato

'Dia kan tetap menggunakan bahasa Banyumas kalau berpidato.'

(11b)\# Teepnganggobasa Baryumasan// kaejen// angger pidhato \#

/ têtêp KaKgo basa bañumasan kaé jên aKgêr pidòato /

\section{\# 231t // 222 // 221t \# \\ $\mathrm{R} \quad$ Sup1 Sup2}

Tetap menggunakan bahasa Banyumas// itu kan// kalau pidato

'Tetap menggunakan bahasa Banyumas, dia itu kalau berpidato.'

Konstruksi (11) yang memiliki dua tema dengan pola konstruksi intonasi 2-23n/ 2-23n/ 231t dapat mengalami perubahan pola konstruksi intonasi dalam dua variasi. Variasi pertama ialah pola intonasi 2-23n/ 231t/ 221t dan variasi kedua ialah pola intonasi 231t/ 222/ 231t.

\subsubsection{Perubahan Pola Intonasi Tipe 4}

Konstruksi tema-rema Tipe 4 ialah pola remasuplemen (R Sup). Artinya, pola itu mensyaratkan hadirnya konstituen rema dan satu suplemen sesudah rema. Namun, konstituen tema boleh hadir dalam tipe itu. Konstruksi ini berpola intonasi 231t/221t. Polaintonasi itu dapat mengalami perubahan menjadi satu variasi, yaitu 2-23n/ 231t, seperti pada contoh berikut.

(12) \# Aja/ / kudume\#

/ aja kuduné/

\# 231t// 221t\#

$\mathrm{R} \quad$ Sup

Jangan// harusnya

'Tidak boleh sebenarnya.'

(12a)\# Kudund / aja \#

/ kuduné aja/

\#2- 23n// 231t \# $\mathrm{T} \quad \mathrm{R}$

Harusnya/ / jangan

'Tidak boleh sebenarnya.'

Pada konstruksi berikut menggambarkan adanya unsur tema yang bukan syarat hadirnya konstituen wajib pada Tipe 4. Oleh karena itu, perubahan yang dibahas difokuskan pada konstituen rema dan suplemen yang berpola intonasi 231t/ 221t. Pada prinsipnya, perubahan pola intonasi Tipe 4 itu ialah intonasi pada konstituen suplemen 221t yang dapat berubah menjadi konstituen tema 2-23n. D engan itu pula ditunjukkan bahwa intonasi pada rema, di mana pun posisinya, tetap tidak berubah. Hal itu menunjukkan keintian atau keutamaan rema.

\subsubsection{Perubahan Pola Intonasi Tipe 5}

Pola intonasi konstruksi tema-rema Tipe 5 ialah 231t/ 222/ 221t. D engan catatan bahwa tipe ini mensyaratkan hadirnya konstituen rema, dan dua suplemen atau lebih. D engan demikian, tidak 
mewajibkan kehadiran konstituen tema. Oleh karena itu, perubahan pola intonasi Tipe 5 hanya terfokus pada konstituen rema dan suplemen (suplemen setelah rema). Berikut adalah contoh konstruksi Tipe 5 beserta pola intonasinya, yang selanjutnya diikuti dengan perubahan pola intonasinya.

(13) \# Gedhal / manfaatel / ngopinyongrika pada\# / gêdòé manfaaté Kgo iñoK rika padòa/ $\mathrm{R}$ Sup1 Sup2

Besar// manfaatnya// untuk saya kamu semua

'Besar manfaatnya untuk kita semua.'

(13a)\# Manfaatel / gechel / nggo inyong rika padha $\#$

/ manfaaté gêdòé Kgo iñoK rika padòa/ $\mathrm{T} \quad \mathrm{R} \quad$ Sup

Manfaatnya// besar// untuk saya kamu semua

'Manfaatnya besar untuk kita semua.' (13b)\# Nggoinyongrika padha/ / manfaatel / gechn\# / Kgo iñoK rika padòa manfaaté gêdòé / T1 $\mathrm{T} 2$ $\mathrm{R}$

Untuk saya kamu semua/ / manfaatnya/ / besar

'Untuk kita semua, manfaatnya besar.'

Konstruksi tema-rema (3.60) berpola \#231t/ / 222/ / 221t\# dengan dua suplemen, yang masing-masing merupakan suplemen lepas yang tidak terikat pada konstituen lain dan bersifat mobil. Oleh karena itu, kedua suplemen itu dapat berubah posisi di depan rema dan menimbulkan variasi pola intonasi yang baru. Variasi itu ada dua, yaitu \#2-23n// 231t// 221t\# dan \#2-23n// 223n// 231t\#.

\subsubsection{Perubahan Pola Intonasi Tipe 6}

Pola intonasi Tipe 6 ialah adanya kontur intonasi // 222// yang terletak pada tengah kons- truksi sebelum rema. Kontur itu menandai konstituen suplemen. Konstruksi seperti itu jarang ditemukan dalam bahasa Jawa dialek Banyumas ngoko di Kabupaten Banyumas karena pada umumnya suplemen terletak pada sesudah rema. Suplemen yang terletak pada tengah konstruksi sebelum rema itu dapat berupa suplemen aposisi atau suplemen biasa yang bersifat bebas. Seandainya suplemen itu bersifat bebas (bukan aposisi), konstituen itu dapat pada posisi sesudah rema. Namun, seandainya suplemen itu bersifat terikat (sebagai aposisi), konstituen itu tidak dapat berubah posisi.

Berikut adalah contoh konstruksi tema-rema Tipe 6 yang berpola intonasi \#2-23n/ / 2-23n/ / 222/ / 231t\# dengan pola urut konstituen tematema-suplemen-rema (T T Sup R).

(3.62)\# Senajan mengko / baryu kume / jeed / kon mbayar \#

/ sênajan mêKko bañu kuwé jéré kon mbayar/

\#2- 23n// 2- 23n// 222 // 231t \#

T1 T2 Sup $R$

Meskipun nanti/ / air itu// katanya/ / disuruh membayar

\section{PENUTUP}

1. Intonasi menjadi salah satu unsur utama (selain bentuk strukturalnya) dalam komunikasi lisan verbal. Dalam komunikasi itu terdapat penyampaian informasi dari pihak 1 ke pihak 2 (dan sebaliknya). D alam penyampaian informasi tersebut, intonasi berperan menentukan mana informasi utama dan mana informasi tambahan, yang secara linguistis dapat dites dengan pelesapan, permutasi, dan parafrasa. Satuan informasi dalam bentuk kalimat itu berkonstruksi tema-rema. D engan demikian, konstruksi tema-rema tidak dapat dilepaskan dari analisis intonasi. 
2. Intonasi pada konstruksi tema-rema dalam bahasa Jawa Banyumas bersifat stabil dan teratur. Kestabilan dan keteraturan itu ditandai dengan konsistensi intonasi pada unsur rema. Dimana pun posisi rema dalam sebuah konstruksi tema-rema, intonasinya tetap, yaitu / / 231t/ / dan tidak dapat dilesapkan. Hal itu menandai bahwa rema adalah unsur terpenting. Hal itu juga dapat diperlihatkan dengan dapatnya unsur tema berubah menjadi unsur suplemen (dengan perubahan posisi dan intonasi), dan sebaliknya, suplemen dapat berubah menjadi tema (dengan perubahan posisi dan intonasi). Kemampuan berubahnya unsur tema dan suplemen tersebut semakin memperkuat bahwa unsur rema adalah unsur yang terpenting/ utama.

3. Berdasarkan kajian yang telah dilakukan terdapat enam tipe pola intonasi konstruksi tema-rema dalam bahasa Jawa Banyumas. Tiap-tiap pola itu (kecuali pola 1) dapat berubah menjadi tipe lain. D alam perubahan itu juga disertai perubahan pola intonasi. D engan demikian, perubahan pola urut (ward arda) pada masing-masing tipe konstruksi temarema dapat memengaruhi perubahan pola intonasi.

* Tulisan ini merupakan bagian dari disertasi yang dikemas ulang menjadi bentuk makalah dan belum pernah dipublikasikan. Disertasi yang dimaksud ialah: Sukesti, Restu. 2012. "Konstruksi TemaRema dalam Bahasa Jawa Banyumas Lisan” Y Yogyakarta: Program Pascasarjana, Fakultas Ilmu Budaya, Universitas Gadjah Mada.

\section{DAFTAR PUSTAKA}

Arifin, Syamsul; Dirgo Sabariyanto; dan Sri Nardiati. 1985. "Tipe-Tipe Kalimat dalam Bahasa Jawa”. Yogyakarta: Proyek Penelitian
Bahasa dan Sastra Indonesia dan Daerah, DIY.

Baryadi, I Praptomo. 2000. "Konstruksi Perurutan Waktu pada Tataran dalam Wacana Bahasa Indonesia: Suatu Kajian tentang Ikonisitas Diagramatik" (D isertasi Doktor). Yogyakarta: Program Pascasarjana Universitas Gadjah Mada Yogyakarta.

Halim, Amran. 1984. Intonasi dalam Hubungannya dengan Sintaksis Bahasa Indanesia. Jakarta: Djambatan.

Halliday, M.A.K.2004. An Introductional to Functional Grammar (third eelition). London, Melbourne, Auckland: Edward Arnold.

Nurlina, Erni Siti; Edi Suwatno; dan Sumadi. 2008. Tema Rera dalam Bahasa Java Yogyakarta: Proyek Penelitian Bahasa dan Sastra Indonesia dan Daerah, D IY.

Poedjoesoedarmo, Gloria. 1974. "Role Structure in Javanese". (D isertasi Universitas Cornel, USA).

Poedjoesoedarmo, G loria; Wedhawati; dan

Laginem. 1981. Beberapa Masalah Sintaksis

Bahasa Java. Jakarta: Pusat Pembinaan dan Pengembangan Bahasa, Departemen Pendidikan dan Kebudayaan.

Poedjosoedarmo, Gloria. 1983. "Pengantar Struktur Wacana”. Makalah dalam Ceramah di Balai Penelitian Bahasa Yogyakarta.

Poedjosoedarmo, Soepomo. 1998/ 1999. "Beberapa masalah Sintaksis pada Bahasa Jawa” (makalah pada Lokakarya Penyusunan Bahan Penyuluhan Bahasa Jawa di Balai Bahasa Yogyakarta).

Subroto, D. Edi; Sunardji; dan Sugiri. Tata Bahasa

Deskniptif Bahasa Jama. Jakarta: D epartemen Pendidikan dan Kebudayaan.

Sudaryanto. 1993. Metode dan Teknik Analisis Bahasa Yogyakarta: D uta Wacana University Press. 
Sugiyono. 2003. "Bahasa Melayu Kutai: Kajian Vachek, Josef. 1966. TheLinguistics Schod of Prage Fonetik Eksperimental dan Psikoakustik" (D isertasi Doktor). Jakarta: Program Studi Linguistik, Program Pascasarjana, Fakultas Ilmu Budaya, Universitas Indonesia.

Blomington \& London: Indiana University Press.

Verhaar, J.W.M. 1970. Teer Linguistik dan Bahasa Indonesia Yogyakarta: Yayasan Kanisius.

Suparno. 1993. Konstruksi Tema Rema dalamBahasa Indonesia Lisan Tidak Resmi Masyarakat Kdamadya Malang Jakarta: Proyek Penelitian dan Pembinaan Bahasa dan Sastra Indonesia dan D aerah Jakarta.

Soemarmo. 1971. "Subject - Predicate, FocusPresupposition, and Topic-Comment in Bahasa Indonesia and Javanese". Disertasi Universitas California, Los Angles.

tik. Yogyakarta: Gadjah Mada University Press.

Wedhawati; G loria Soepomo; dan Laginem. 1979. Wacana Bahasa Jama Jakarta: Pusat Pembinaan dan Pengembangan Bahasa, D epartemen Pendidikan dan Kebudayaan. 